\title{
BMJ open Elevated plasma GLP-1 levels and enhanced expression of cardiac GLP-1 receptors as markers of left ventricular systolic dysfunction: a cross-sectional study
}

\author{
Arihiro Hattori, Itta Kawamura, Yoshihisa Yamada, Hiromitsu Kanamori, \\ Takuma Aoyama, Hiroaki Ushikoshi, Masanori Kawasaki, Kazuhiko Nishigaki, \\ Genzou Tamemura, Shinya Minatoguchi
}

To cite: Hattori A,

Kawamura I, Yamada Y, et al. Elevated plasma GLP-1 levels and enhanced expression of cardiac GLP-1 receptors as markers of left ventricular systolic dysfunction: a crosssectional study. BMJ Open 2013;3:e003201.

doi:10.1136/bmjopen-2013003201

- Prepublication history for this paper is available online. To view these files please visit the journal online (http://dx.doi.org/10.1136/ bmjopen-2013-003201).

Received 10 May 2013 Revised 26 July 2013 Accepted 29 July 2013

Department of Cardiology, Gifu University Graduate School of Medicine, Gifu, Japan

Correspondence to Shinya Minatoguchi; minatos@gifu-u.ac.jp

\section{ABSTRACT}

Objective: We aimed to elucidate usefulness of plasma glucagon-like peptide-1 (GLP-1) levels for the assessment of left ventricular (LV) dysfunction by examining the relationship among plasma GLP-1 levels, expression of cardiac GLP-1 receptors and LV function in patients with impaired and preserved LV function.

Design: Prospective study.

Setting: Number of participating center: 1, Gifu, Japan.

Participants: Number of patients enrolled: 102 patients who underwent elective cardiac catheterisation for coronary artery disease, cardiomyopathy and valvular heart disease, and 6 patients who underwent cardiac biopsy.

Results: The plasma GLP-1 level was significantly increased in patients with impaired LV function $(5.7 \pm 1.9 \mathrm{pmol} / \mathrm{L})$ as compared with those with preserved LV function $(2.7 \pm 1.6 \mathrm{pmol} / \mathrm{L})$. Plasma GLP-1 and plasma brain natriuretic peptide (BNP) levels were inversely correlated with the LV ejection fraction(EF), respectively. Plasma GLP-1 level positively correlated with plasma BNP level. Multivariate logistic regression analysis revealed that plasma GLP-1 level was an independent determinant of the impaired LV function, whereas plasma BNP level was not. Intensity of immunostaining for GLP-1 receptor protein was significantly enhanced in patients with impaired LV function compared with those with preserved LV function.

Conclusions: The plasma GLP-1 level was increased in patients with impaired systolic LV function and inversely correlated with the LVEF. The expressions of GLP-1 receptors were enhanced in hearts with impaired LV function. These may suggest that endogenous GLP-1-GLP-1 receptor system serves as a compensatory mechanism for systolic LV dysfunction.

Trial registration: UMIN-CTR, ID=UMIN000009361, registration number: R000011000.

\section{ARTICLE SUMMARY}

Article focus

- Fasting plasma glucagon-like peptide-1 (GLP-1) level has not yet been clarified in patients with left ventricular (LV) dysfunction. Relationship between plasma GLP-1 level and LV ejection fraction (EF), and between plasma GLP-1 level and plasma brain natriuretic peptide (BNP) level, an indicator of heart failure, has not yet been clarified. The expression of GLP-1 receptor in the myocardium in patients with LV dysfunction has not yet been clarified.

Key messages

- The plasma GLP-1 level was significantly increased in patients with impaired LV function as compared with those with preserved LV function. Plasma GLP-1 level was inversely correlated with the LV $\mathrm{EF}$, and plasma GLP-1 level positively correlated with plasma BNP level. Plasma GLP-1 level was an independent determinant of the impaired LV function, whereas plasma BNP level was not. The expression of GLP-1 receptor assessed by the intensity of immunostaining for GLP-1 receptor protein obtained from cardiac biopsied tissue samples was significantly enhanced in patients with impaired LV function as compared with those with preserved LV function.

Strengths and limitations of this study

- The expression of GLP-1 and GLP-1 receptor was assessed by human endomyocardial biopsy samples obtained from patients with heart disease. The biopsy samples were obtained only from patients who definitely needed histological diagnosis and not from normal patients without heart diseases because it is ethically impossible to obtain endomyocardial biopsy samples from normal patients. 


\section{INTRODUCTION}

Glucagon-like peptide-1 (GLP-1) is one of the two physiological hormones that meet the criteria of 'incretin', which is released from the intestine in response to nutrients and exerts a potent insulin-releasing effect on pancreatic $\beta$-cells. ${ }^{1}$ It is now well established that GLP-1-induced insulin secretion leads to significant postprandial glucose lowering in both diabetic animal models and patients with type 2 diabetes. ${ }^{1}$ The major active form of GLP-1 is a GLP-1(7-36) amide $^{2}$ and, following its release into the circulation, GLP-1(7-36) amide undergoes rapid enzymatic degradation by dipeptidyl peptidase-4 (DPP-4) ${ }^{3}$ into GLP-1(9-36) amide by the removal of an N-terminal dipeptide, which is an inactive form. ${ }^{4}$ It has also been reported that stimulation of GLP-1 receptors protects the heart against ischaemia-reperfusion injury in animal studies ${ }^{5-7}$ and in humans. ${ }^{8} 9$ There are very few studies that have investigated plasma GLP-1 level in cardiac disease. One is the report showing that fasting plasma GLP-1 level was lower in patients with coronary artery disease than in those without. ${ }^{10}$ However, difference in mean value of fasting plasma GLP-1 was quite small. ${ }^{10}$ The other report is that plasma GLP-1 level was associated with diastolic heart function but not with systolic heart function in elderly men who were invited to a healthy survey. ${ }^{11}$ However, it is not still clear whether endogenous plasma GLP-1 is related to left ventricular (LV) systolic function in cardiac patients with LV dysfunction. Therefore, the aim of the current study was (1) to elucidate the usefulness of plasma GLP-1 levels for the assessment of LV dysfunction comparing plasma GLP-1 levels with conventional parameters, such as brain natriuretic peptide (BNP) and the ratio of mitral inflow E-wave to A-wave velocity (E/A), and (2) to compare the expression of GLP-1 and GLP-1 receptor proteins immunohistochemically in myocardial biopsied samples obtained from patients who definitely needed histological diagnosis between patients with preserved and impaired LV function.

\section{METHODS}

The protocol of the current study was approved by the Ethics Committee of Gifu University Graduate School of Medicine. All patients gave informed consent before the study started. The investigation conforms with the principles outlined in the Declaration of Helsinki (BMJ 1964; ii:177).

\section{Study patients}

A total of 102 patients who underwent elective cardiac catheterisation for coronary artery disease, cardiomyopathy and valvular heart disease were enrolled. All patients underwent coronary angiography and in some patients left ventriculogram was performed. LV ejection fraction (EF), a marker of systolic LV function, and a ratio of mitral inflow $\mathrm{E}$-wave to A-wave velocity (E/A), a marker of diastolic LV function, were obtained by echocardiography. According to the LVEF, patients were divided into two groups: preserved $\mathrm{LV}$ function group with $\mathrm{EF}$ equal to or more than $55 \%$, and impaired $\mathrm{LV}$ function group with $\mathrm{EF}$ less than $55 \%$. LV end-systolic volume and LV end-diastolic volume were indexed for body surface area.

\section{Measurements of plasma GLP-1 and BNP levels}

Blood samples were obtained from the antecubital vein in the morning before breakfast while the patients were in a fasting state on the day of cardiac catheterisation. The samples were collected into sterile tubes, immediately placed on ice, and centrifuged at $3000 \times g$ for $10 \mathrm{~min}$ at $4^{\circ} \mathrm{C}$, and rapidly frozen and stored at $-80^{\circ} \mathrm{C}$ until analysis. We added $10 \mu \mathrm{L}$ of DPP-4 inhibitor (DPP4/DPP4-010, Linco Research Inc, St Charles, Missouri, USA) to one $\mathrm{mL}$ of blood at the time of blood sampling to inhibit GLP-1 degradation. Plasma GLP-1 levels were measured using an ELISA kit (LINCO Research Inc). This ELIZA kit can detect GLP-1(7-36) and GLP-1(7-37). Plasma BNP levels were measured by immunoradiometric assays (Shionoria BNP RIA kit; Shionogi, Osaka, Japan). We also measured fasting blood sugar, HbAlc and immunoreactive insulin (IRI) as a marker of glucose metabolism, and examined its relationship with plasma GLP-1 levels.

\section{Immunohistochemical analysis of GLP-1 and GLP-1} receptor proteins in the endomyocardial biopsy samples We obtained endomyocardial biopsy samples from patients with preserved LV function and impaired LV function. These included six patients with preserved $\mathrm{LV}$ function (3 hypertrophic cardiomyopathy, 2 postmyocarditis and 1 idiopathic VT) and six patients with impaired LV function (four dilated cardiomyopathy, one peripatum cardiomyopathy, one postmyocarditis). Endomyocardial biopsy samples were fixed in $10 \%$ formalin, embedded in paraffin and serially cut into $5 \mu \mathrm{m}$-thick sections. These sections were subjected to an indirect immunoperoxidase method for immunohistochemical staining. The primary antibodies used were mouse monoclonal (8G9) to GLP-1 (Abcam (ab26278); dilution 1:100 $(10 \mu \mathrm{g} / \mathrm{mL}))$ and GLP-1 receptor rabbit antihuman polyclonal antibody (MBL LS-A1208; dilution 1:50 $(20 \mu \mathrm{g} / \mathrm{mL}))$.

Each stained section was examined under a microscope (Nikon) connected to a computerised imageanalysis system (LUZEX F multipurpose colour image processor; Nireco). The intensity of protein expression was estimated according to the following criteria: 0 : no staining, 1+: very weak staining, 2+: weak staining, 3+: moderate staining, 4+: enhanced staining; 5+: markedly enhanced staining. Morphometric analysis was performed by two pathologists blinded to any knowledge of the patient profiles. To evaluate the reliability of scoring immunohistochemical images, we measured an overall agreement of the histological grade between two readers. 


\section{Statistical analysis}

All data are shown as the mean $\pm \mathrm{SD}$. Categorical data were summarised as percentages and compared with a $\chi^{2}$ test. For comparison between the two groups, an unpaired $t$ test was used. Linear regression analysis was performed to examine the correlations between each LV parameter and the GLP-1 and BNP levels and other parameters. The degrees of immunostaining for GLP-1 and GLP-1 receptor proteins in the biopsied myocardial samples were compared between the groups with preserved and impaired LV function using an unpaired t test. Multivariate logistic regression analysis was performed to identify the independent predictors of $L V$ dysfunction. A $p$ value $<0.05$ was considered to be significant. All statistical analyses were performed using Stat View V.5.0 (SAS Institution Inc, Cary, North Carolina, USA).

\section{RESULTS}

\section{Patients' characteristics}

Patients' clinical characteristics are as shown in table 1. The patients were orally administered ACE inhibitors $(\mathrm{n}=15)$, angiotensin II receptor blockers $(\mathrm{n}=55)$, calcium channel blockers $(n=37), \beta$-blockers $(n=48)$ and diuretics $(n=46)$. There were no significant differences in age, gender, coronary risk factors between the preserved systolic LV function group and the impaired systolic LV function group. However, $\beta$-blockers and diuretics were more frequently administrated in the impaired systolic LV function group than the preserved systolic LV function group based on the treatment of heart failure.

\section{Plasma levels of GLP-1 and BNP}

As shown in figure 1, the plasma GLP-1 level was significantly higher in the impaired LV function group $(5.71 \pm 1.9 \mathrm{pmol} / \mathrm{L})$ than in the preserved $\mathrm{LV}$ function $(2.72 \pm 1.6 \mathrm{pmol} / \mathrm{L})$. The plasma BNP level was also significantly higher in the impaired $\mathrm{LV}$ function group $(607 \pm 611 \mathrm{pg} / \mathrm{mL})$ than in the preserved $\mathrm{LV}$ function group $(118 \pm 186 \mathrm{pg} / \mathrm{mL})$.

Relationships among plasma GLP-1, BNP levels and LVEF, and relationship between plasma GLP-1 levels and E/A Plasma GLP-1 levels were negatively correlated with LVEF, an indicator of LV systolic function $(\mathrm{r}=0.71, \mathrm{p}<0.001$,

Table 1 Patients' clinical and echocardiographic characteristics and cardiac catheterisation data

\begin{tabular}{|c|c|c|c|}
\hline & Preserved LV function $(n=53)$ & Impaired LV function $(n=49)$ & p Value \\
\hline Age (year) & $67.8 \pm 11.4$ & $682 \pm 13.5$ & 0.87 \\
\hline Male, n (\%) & $35(66)$ & $32(65)$ & 0.95 \\
\hline Weight (kg) & $60.6 \pm 12.5$ & $58.3 \pm 12.7$ & 0.35 \\
\hline Height (cm) & $160 \pm 10$ & $159 \pm 11$ & 0.76 \\
\hline Body mass index $\left(\mathrm{kg} / \mathrm{m}^{2}\right)$ & $23.7 \pm 3.63$ & $22.9 \pm 3.99$ & 0.77 \\
\hline Systolic blood pressure (mm Hg) & $126.5 \pm 15.4$ & $120.5 \pm 20.9$ & 0.095 \\
\hline Diastolic blood pressure $(\mathrm{mm} \mathrm{Hg})$ & $72.9 \pm 10.2$ & $66.7 \pm 13.6$ & 0.010 \\
\hline Diabetes mellitus, n (\%) & $19(36)$ & $25(51)$ & 0.12 \\
\hline Hypertension, n (\%) & $34(64)$ & $25(51)$ & 0.18 \\
\hline Dyslipidaemia, n (\%) & $37(70)$ & $25(51)$ & 0.052 \\
\hline Coronary artery disease, $\mathrm{n}(\%)$ & $40(75)$ & $31(63)$ & 0.18 \\
\hline ARBs or ACEls, $n(\%)$ & $38(72)$ & $28(57)$ & 0.12 \\
\hline$\beta$-Blockers, n (\%) & 17 (32) & $31(63)$ & 0.002 \\
\hline Statins, n (\%) & $26(49)$ & $23(47)$ & 0.83 \\
\hline Calcium channel blockers, n (\%) & $20(38)$ & $17(35)$ & 0.10 \\
\hline Diuretics, n (\%) & $13(25)$ & $33(67)$ & $p<0.001$ \\
\hline Blood sugar (mg/dL) & $108.3 \pm 23.0$ & $120.4 \pm 33.6$ & 0.035 \\
\hline Glycated haemoglobin $\mathrm{HbA} 1 \mathrm{c}(\%)$ & $6.07 \pm 1.27$ & $6.13 \pm 1.17$ & 0.79 \\
\hline Immunoreactive insulin ( $\mu \mathrm{U} / \mathrm{mL})$ & $8.84 \pm 8.22$ & $11.3 \pm 20.3$ & 0.42 \\
\hline HOMA-IR & $2.39 \pm 2.44$ & $3.44 \pm 5.80$ & 0.23 \\
\hline Estimated GFR $\left(\mathrm{mL} / \mathrm{min} / 1.73 \mathrm{~m}^{2}\right)$ & $69.7 \pm 17.4$ & $54.4 \pm 28.7$ & 0.001 \\
\hline$C$ reactive protein (mg/dL) & $0.69 \pm 2.26$ & $2.41 \pm 4.53$ & 0.015 \\
\hline GLP-1 (pmol/L) & $2.72 \pm 1.56$ & $5.71 \pm 1.95$ & $p<0.001$ \\
\hline Brain natriuretic peptide (pg/mL) & $118 \pm 186$ & $607 \pm 611$ & $p<0.001$ \\
\hline LVEDVI $\left(\mathrm{mL} / \mathrm{m}^{2}\right)$ & $81.8 \pm 22.2$ & $124.1 \pm 50.9$ & $p<0.001$ \\
\hline LVESVI (mL/m²) & $26.4 \pm 12.9$ & $71.8 \pm 43.0$ & $p<0.001$ \\
\hline Cardiac index $\left(\mathrm{L} / \mathrm{min} / \mathrm{m}^{2}\right)$ & $3.99 \pm 1.16$ & $3.73 \pm 1.36$ & 0.34 \\
\hline LVEF (\%) & $62.0 \pm 4.47$ & $41.7 \pm 10.2$ & $p<0.001$ \\
\hline$E / A$ & $0.77 \pm 0.19$ & $0.78 \pm 0.30$ & 0.24 \\
\hline
\end{tabular}

Data are presented as the number (\%) of patients or the mean \pm SD.

ARBs, angiotensin II receptor blockers; E/A, the ratio of mitral inflow E-wave to A-wave velocity; GFR, glomerular filtration rate; GLP-1, glucagon-like peptide-1; LVEDVI, left ventricular end-diastolic volume index; LVEF, left ventricular ejection fraction; LVESVI, left ventricular end-systolic volume index. 
Figure 1 Plasma levels of glucagon-like peptide-1 (GLP-1) and brain natriuretic peptide (BNP) in patients with preserved left ventricular (LV) function $(n=53)$ and impaired LV function $(n=49)$, Plasma GLP-1 and plasma BNP levels were significantly higher in patients with impaired LV function than in, patients with preserved LV function $\left({ }^{*} p<0.001\right)$.
Plasma GLP-1 Levels

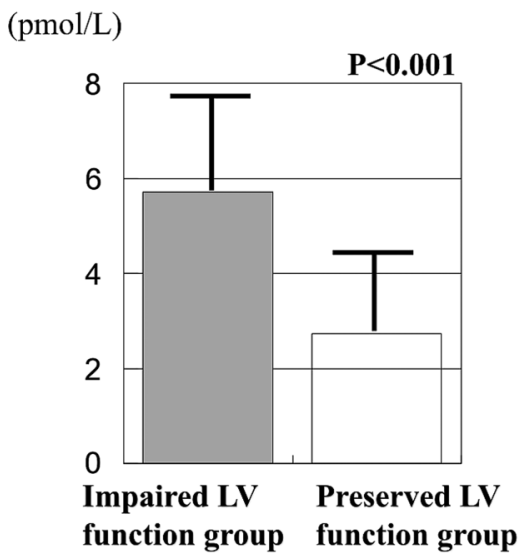

Plasma BNP Levels

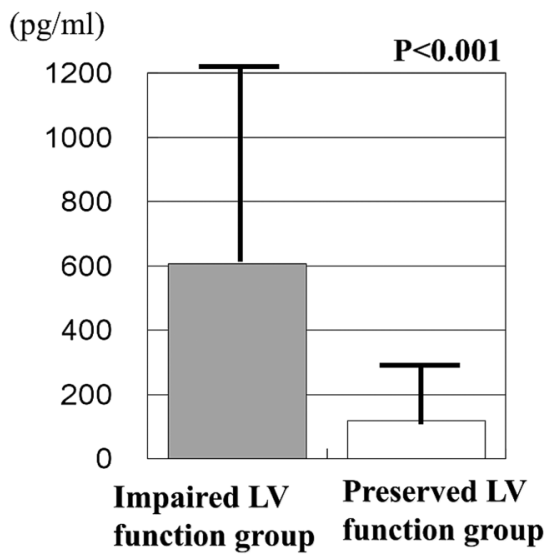

figure 2A). The plasma BNP level was negatively correlated with the LVEF $(r=0.61, p<0.001$, figure 2B). The plasma GLP-1 levels were positively correlated with the plasma BNP levels $(\mathrm{r}=0.55, \mathrm{p}<0.001$, figure $2 \mathrm{C}$ ). However, there was no relationship between the plasma GLP-1 level and E/A, an indicator of diastolic LV function (figure 2D). Echocardiographic and clinical parameters with a $\mathrm{p}$ value $<0.005$ in an unpaired test and $\chi^{2}$ test were included in multivariate logistic regression analysis. However, LV endsystolic volume index was excluded due to multicollinearity because there was a strong correlation between LV end-systolic volume index and LV end-diastolic volume index $(\mathrm{r}=0.91, \mathrm{p}<0.001)$. The plasma GLP-1 level and LV end-diastolic volume index were independent determinants of the impaired LV function, whereas plasma BNP level or E/A was not an independent determinant of the impaired LV function (table 2).

\section{Relationships among plasma GLP-1, HbA1c, IRI and} HOMA-IR

There was no relationship between the plasma GLP-1 level and HbA1c (figure 3A), between the plasma GLP-1
A

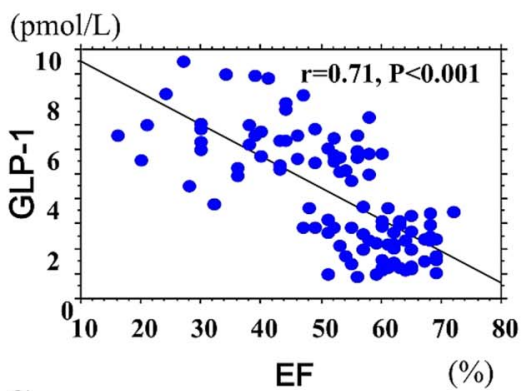

C

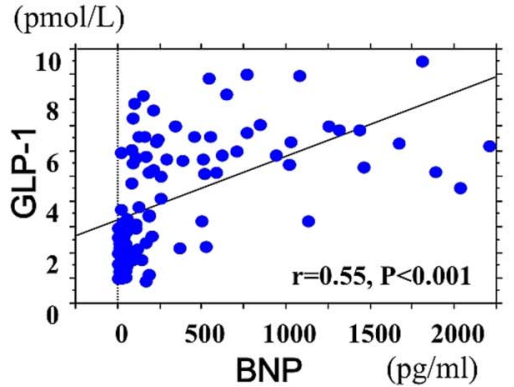

B

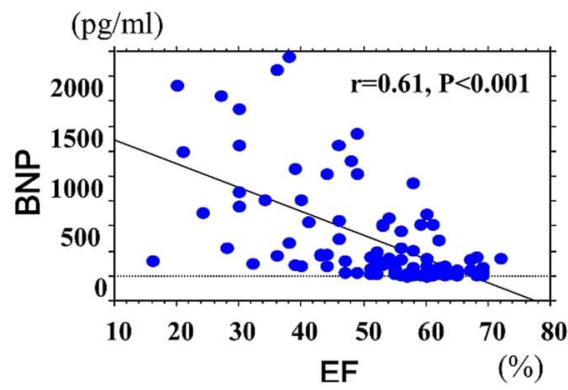

D

$(\mathrm{pmol} / \mathrm{L})$

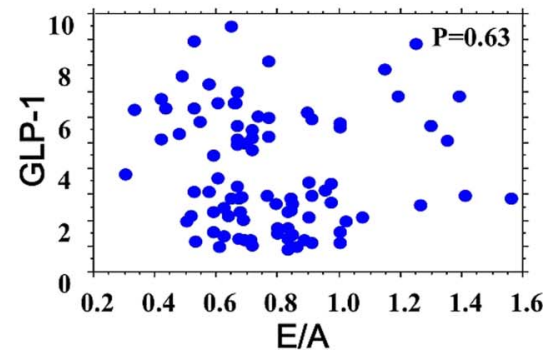

Figure 2 Relationships among plasma levels of glucagon-like peptide-1 (GLP-1), brain natriuretic peptide (BNP) and left ventricular ejection fraction (LVEF), and relationship between plasma GLP-1 levels, and E/A, (A) relationship between plasma GLP-1 level and EF ( $n=102)$, (B) relationship between plasma BNP level and EF $(n=102)$, (C) relationship between plasma GLP-1 level and plasma BNP level ( $n=102)$, (D) relationship between plasma GLP-1 level and E/A ( $n=88), P a t i e n t s$ with pseudonormalisation of $E / A$ and, patients with atrial fibrillation were excluded because $E / A$ does not necessarily reflect LV diastolic function in, these patients. Plasma GLP-1 levels or plasma BNP levels were negatively correlated with LVEF. Plasma GLP-1 levels were, positively correlated with plasma BNP levels. There was no correlation between plasma GLP-1 level and E/A, an indicator of LV diastolic function. 
Table 2 Independent predictor of left ventricular dysfunction based on multivariate logistic regression analysis

\begin{tabular}{llll}
\hline Variables & OR & $\mathbf{9 5 \%}$ Cl & $\mathbf{p}$ Value \\
\hline GLP-1 & 1.854 & 1.232 to 2.788 & 0.003 \\
Brain natriuretic peptide & 1.003 & 0.999 to 1.006 & 0.11 \\
LV end-diastolic volume & 1.031 & 1.007 to 1.055 & 0.010 \\
index & & & \\
Estimated GFR & 1.006 & 0.973 to 1.040 & 0.71 \\
B-Blockers & 2.139 & 0.570 to 8.019 & 0.26 \\
Diuretics & 1.117 & 0.221 to 5.623 & 0.89 \\
\hline GLP-1, glucagon-like peptide-1; LV, left ventricular; & \\
GFR, glomerular filtration rate. & &
\end{tabular}

level and IRI (figure 3B), or between plasma GLP-1 level and HOMA-IR (figure 3C).

Immunohistochemical analysis of GLP-1 and GLP-1 receptor proteins in endomyocardial biopsy samples

Figure 4A,B shows typical cases of immunostaining of GLP-1 receptor proteins and GLP-1 protein in endomyocardial biopsy samples, respectively. The overall agreement of the histological grade between two readers was excellent (Cohen's $\kappa=0.87,95 \%$ CI 0.68 to 1.00 ). Table 3 shows the clinical profiles and the intensity of immunostaining for GLP-1 and GLP-1 receptor proteins in six patients with preserved LV function and six patients with impaired LV function. There was no difference in the intensity of immunostaining for GLP-1 protein between patients with impaired LV function and those with preserved LV function (table 3). The intensity of immunostaining for GLP-1 receptor protein in patients with impaired LV function was significantly higher than that in patients with preserved $\mathrm{LV}$ function $(\mathrm{p}<0.05$; figure $4 \mathrm{C})$.

\section{DISCUSSION}

In the current study, we found that plasma GLP-1 level was significantly increased in patients with impaired $\mathrm{LV}$ function as compared with those with preserved LV function. Plasma GLP-1 and plasma BNP levels were inversely correlated with the LVEF, respectively. Plasma GLP-1 level positively correlated with plasma BNP level. Intensity of immunostaining for GLP-1 receptor protein was significantly enhanced in patients with impaired LV function compared with those with preserved LV function. Multivariate analysis demonstrated that the plasma GLP-1 level and LV end-diastolic volume index were independent determinants of the impaired LV function, whereas plasma BNP level or E/A was not an independent determinant of the impaired LV function.

\section{GLP-1 and its cardioprotective effect}

GLP-1 is a 30 amino acid intestinal hormone secreted in a nutrient-dependent manner, and stimulates insulin secretion, thereby reducing postprandial hyperglycaemia. ${ }^{12}$ GLP-1 also reportedly mitigates postischaemic myocardial dysfunction and reduces myocardial infarct size in rats $^{2}{ }^{3}$ and swine. ${ }^{4}$ In an isolated rat heart with global ischaemia and reperfusion, exogenously administered GLP-1 or GLP-1 agonist exenatide immediately after reperfusion reduced the infarct size. ${ }^{13}{ }^{14} \mathrm{In}$ an in vivo rat or porcine model of myocardial infarction, intravenous infusion of GLP-1 or GLP-1 agonist exenatide significantly reduced the infarct size. ${ }^{5}$ We previously reported that oral administration of voglibose and miglitol significantly increased basal and postprandial plasma
Figure 3 Relationships among plasma levels of glucagon-like peptide-1 (GLP-1), glycated haemoglobin (HbA1c), immunoreactive insulin (IRI) and HOMA-IR (A) relationship between plasma GLP-1 level and $\mathrm{HbA1c}(\mathrm{n}=102)$, (B) relationship between plasma GLP-1 level and IRI $(n=102)$, (C) relationship between plasma GLP-1 level and HOMA-IR $(n=102)$, plasma GLP-1 levels did not correlate with HbA1c, IRI or HOMA-IR.
A

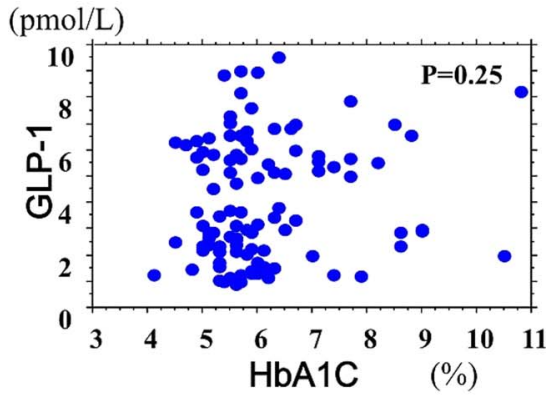

B

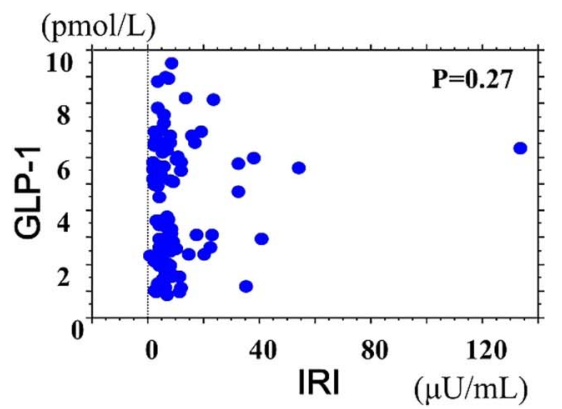

C (pmol/L)

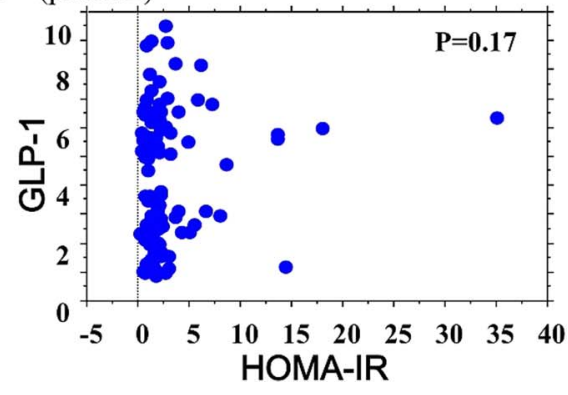


A
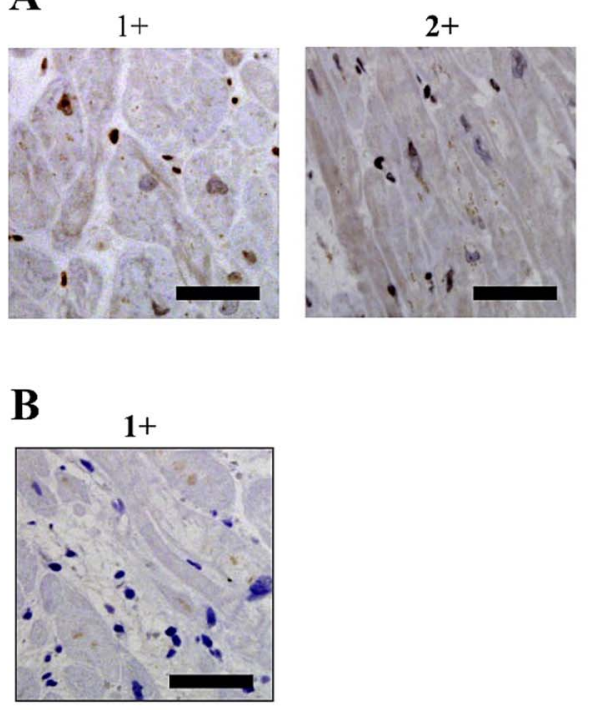

$\mathrm{Bar}=50 \mu \mathrm{m}$
$3+$

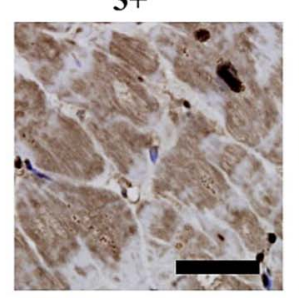

4+

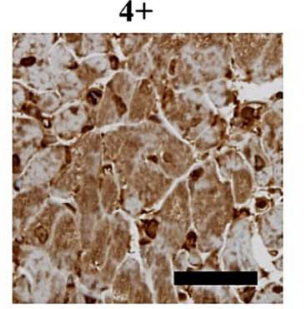

$5+$

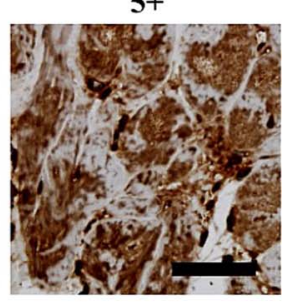

GLP-1 Receptor

$\mathrm{C}$

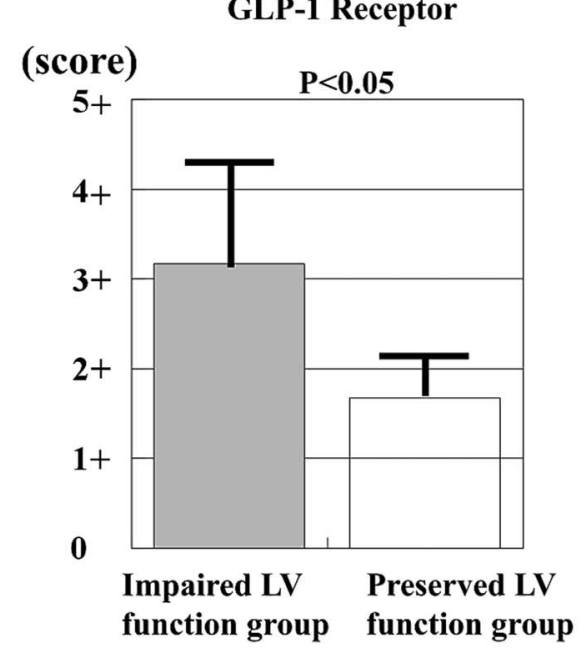

Figure 4 (A) Representative images of immunostaining for glucagon-like peptide-1 (GLP-1) receptor in endomyocardial biopsy samples, $1+$ : very weak staining, 2+: weak staining, 3+: moderate staining, 4+: enhanced staining; $5+$ : markedly enhanced staining. (B) Representative image of immmunostaining for GLP-1 in endomyocardial biopsy sample, 1+: very weak staining, (C) mean quantified data for GLP-1 receptor expression intensity of GLP-1 receptor expression was significantly greater in the impaired left ventricular (LV) function group than in the preserved LV function group. Score of intensity of GLP-1 receptor expression: impaired LV function group $=3.2 \pm 1.2$, preserved LV function group $=1.7 \pm 0.5$.

levels of GLP-1 and the increased endogenous GLP-1 significantly improved cardiac function and reduced the myocardial infarct size. ${ }^{15} 16$ Furthermore, the expression of GLP-1 receptors was enhanced in the myocardium of rabbits with myocardial infarction. ${ }^{15}{ }^{16}$ These results suggest that endogenous GLP-1 as well as exogenous

Table 3 Characteristics of patients with preserved and impaired LV function and intensity of immunostaining for GLP-1 and GLP-1 receptor

\begin{tabular}{|c|c|c|c|c|c|c|c|}
\hline \multirow[b]{2}{*}{ Gender } & \multirow[b]{2}{*}{ Age } & \multirow[b]{2}{*}{ LVEDD } & \multirow[b]{2}{*}{ LVEF } & \multirow[b]{2}{*}{ BNP } & \multirow[b]{2}{*}{ Diagnosis } & \multicolumn{2}{|c|}{ Intensity of immunostaining } \\
\hline & & & & & & $\overline{\text { GLP-1 }}$ & GLP-1 receptor \\
\hline \multicolumn{8}{|c|}{ Preserved LVEF ( $\geq 55 \%)$} \\
\hline Male & 63 & 55 & 68 & 60 & $\mathrm{HCM}$ & $1+$ & $2+$ \\
\hline Male & 51 & 48 & 58 & 7 & Post-MC & $1+$ & $2+$ \\
\hline Male & 77 & 37 & 75 & 33 & Post-MC & $1+$ & $2+$ \\
\hline \multicolumn{8}{|c|}{ Impaired LVEF (<55\%) } \\
\hline Male & 70 & 72 & 24 & 241 & DCM & $1+$ & $2+$ \\
\hline Male & 70 & 55 & 25 & 4250 & DCM & $1+$ & $3+$ \\
\hline Male & 48 & 61 & 37 & 307 & DCM & $1+$ & $3+$ \\
\hline Female & 33 & 66 & 27 & 758 & PPCM & $1+$ & $4+$ \\
\hline
\end{tabular}


GLP-1 has a cardioprotective effect. In the current study, the plasma GLP-1 level was significantly higher in the impaired LV function group than in the normal LV function group, and plasma GLP-1 levels were negatively correlated with LVEF, suggesting that elevated plasma GLP-1 levels may contribute to improve the impaired LV function. In humans, it has already been reported that GLP-1 treatment improves myocardial function in patients with heart failure, ${ }^{17}{ }^{18}$ supporting the concept that elevated endogenous plasma GLP-1 improves LV dysfunction.

\section{Increased plasma GLP-1 levels in impaired LV function and plasma BNP levels}

The plasma BNP level has been reported to be increased in patients with congestive heart failure and has been established as a good indicator of the severity of congestive heart failure. ${ }^{19}$ The plasma BNP level has also been reported to be elevated in patients with $\mathrm{LV}$ dysfunction. ${ }^{20}$ Consistent with these reports, in the current study, plasma BNP levels were increased in patients with impaired LV function. Plasma BNP levels were negatively correlated with LVEF. Increased plasma BNP has been considered to be a compensatory mechanism for congestive heart failure. ${ }^{21}$ The new findings in the current study was that plasma GLP-1 levels were increased in patients with impaired LV function and that plasma GLP-1 levels were negatively correlated with LVEF. This behaviour was quite similar to that of plasma BNP. Plasma GLP-1 levels were positively correlated with plasma BNP levels in the current study. However, multivariate analysis showed that the plasma GLP-1 level was an independent determinant of the impaired LV function, whereas plasma BNP level or E/A was not an independent determinant of the impaired LVEF. The E/A has been proposed to estimate diastolic LV dysfunction. ${ }^{22}$ Therefore, plasma GLP-1 level was supposed to be a marker of systolic LV function rather than diastolic LV dysfunction. Likewise, plasma BNP level was proposed to estimate heart failure. ${ }^{202123}$ The current study suggested that the plasma GLP-1 level was supposed to be a more useful marker for systolic LV dysfunction than plasma BNP levels. In addition, negative correlation between plasma GLP-1 level and LVEF may reflect that secretion of GLP-1 from the intestine is facilitated by a reduction of blood flow in the intestine caused by a reduced LVEF. Very recently, cardiac GLP-1 receptor activation has been reported to promote the secretion of atrial natriuretic peptide in mice. ${ }^{24}$ This may support the positive correlation between plasma GLP-1 and BNP levels. It was reported that plasma levels of GLP-1 had weak correlation with diastolic function in elderly men $(\mathrm{r}=0.19) .{ }^{11}$ However, this correlation was demonstrated by univariate analysis. In the current study, multivariate analysis revealed that the plasma GLP-1 level was associated with markers for systolic LV dysfunction rather than markers for diastolic LV dysfunction.
It has also been reported that plasma fasting levels of GLP-1 were significantly lower in patients with coronary artery disease. ${ }^{10}$ In the current study, however, there was no significant difference in plasma GLP-1 levels between patients with $(4.0 \pm 2.2 \mathrm{pmol} / \mathrm{L})$ and without $(4.5$ $\pm 2.6 \mathrm{pmol} / \mathrm{L}$ ) coronary artery disease. Plasma GLP-1 levels inversely correlated with the LVEF, an indicator of systolic LV function, regardless of the absence or presence of coronary artery disease.

Since GLP-1 is released from the intestine in response to nutrients, plasma GLP-1 levels may be affected by food. Therefore, in the current study, to avoid the effect of food, blood samples for the measurement of plasma GLP-1 were taken in the morning before breakfast in a fasting state. Even in this situation, plasma GLP-1 was higher in patients with impaired LV function than in those with normal LV function. Since GLP-1 is involved in postprandial insulin secretion, plasma GLP-1 levels may be influenced by plasma glucose or plasma insulin levels. However, there was no relationship between plasma GLP-1 levels and HbA1c, between plasma GLP-1 levels and IRI or between plasma GLP-1 levels and HOMA-IR, suggesting that fasting plasma GLP-1 levels were not affected by blood glucose or plasma insulin levels or insulin resistance. Plasma GLP-1 levels are determined by the balance between the release of GLP-1 from the intestine into the circulation and rapid enzymatic degradation of GLP-1 by DPP- $4 .{ }^{3}$ Therefore, plasma DPP-4 activity is also a determinant of plasma GLP-1 levels. Whether LV dysfunction decreases plasma DPP-4 remains to be elucidated.

\section{Immunohistochemical detection of myocardial GLP-1 and GLP-1 receptors}

We examined the expression of GLP-1 and GLP-1 receptor proteins immunohistochemically in endomyocardial biopsy samples obtained from patients with preserved and impaired LV function. GLP-1 and GLP-1 receptor proteins were stained in the myocardium. There was no significant difference in the expression of GLP-1 protein between patients with preserved and impaired LV function. GLP-1 is primarily released from the intestine in response to nutrients and is not produced from the heart. This may explain the reason why tissue GLP-1 levels were not increased in the heart. However, the expression of GLP-1 receptor protein was significantly enhanced in patients with impaired LV function as compared with those in patients with preserved LV function. This was supported by our previous animal studies demonstrating that the expression of GLP-1 receptors in the $\mathrm{LV}$ myocardium was upregulated in a rabbit model of myocardial infarction, ${ }^{15}{ }^{16}$ and other report that the cardiac GLP-1 receptors were upregulated in a heart failure dog model of dilated cardiomyopathy. ${ }^{25}$ This may support the concept that GLP-1-GLP-1 receptor system may serve as a compensatory mechanism for $\mathrm{LV}$ dysfunction. 
Therefore, higher plasma GLP-1 in patients with impaired LV function may more strongly stimulate upregulated cardiac GLP-1 receptors, and thus more strongly stimulate its downstream prosurvival signal transduction, such as the PI3K-Akt-eNOS pathway, ${ }^{15}{ }^{16}$ and may improve LV dysfunction. As a matter of fact, we previously investigated the effect of oral administration of $\alpha$-glucosidase inhibitors voglibose and miglitol on myocardial infarct size, and found that myocardial infarction caused upregulation of cardiac GLP-1 receptor and $\alpha$-glucosidase inhibitors increased plasma GLP-1 levels and stimulated myocardial GLP-1 receptor and activated its downstream signals, such as PI3K, Akt and eNOS, and reduced the myocardial infarct size and improved LV function in a rabbit model of myocardial infarction. ${ }^{15} 16$ Thus, the GLP-1 receptor-mediated signal transduction may have contributed to the improvement of $L V$ function in patients with impaired LV function.

\section{Study limitations}

The endomyocardial biopsy samples were obtained only from patients with heart diseases who definitely needed histological diagnosis and not from normal patients without heart diseases because it is ethically impossible to obtain endomyocardial biopsy samples from normal patients; therefore, the behaviour of myocardial GLP-1 and GLP-1 receptor in normal patients remains to be investigated.

\section{CONCLUSIONS}

The plasma GLP-1 was increased in patients with impaired systolic LV function and inversely correlated with the LVEF. The expressions of GLP-1 receptors were enhanced in hearts with impaired LV function. These may suggest that endogenous GLP-1-GLP-1 receptor system serves as a compensatory mechanism for systolic LV dysfunction.

\section{Acknowledgements The authors thank Miss Akiko Tsujimoto for technical assistance.}

Contributors $\mathrm{AH}$ and IK took blood samples from the patients and measured plasma GLP-1 and BNP levels. AH, YY, TA and HU performed cardiac catheterisation and measured haemodynamic parameters. MK performed statistical analysis. KN performed cardiac biopsies. HK and GT performed immunostaining of biopsied samples. AH and SM wrote the article. SM organised and summerised this clinical research.

Funding This work was supported by a grant from Ministry of Education, Culture, Sports, Science and Technology of Japanese Government (to $\mathrm{AH}$ and SM). Grant-in-Aid for Scientific Research (C) (22590775) (2010-2012).

\section{Competing interests None.}

Patient consent Obtained

Ethics approval Gifu University Graduate School of Medicine.

Provenance and peer review Not commissioned; externally peer reviewed.

Data sharing statement No additional data are available.

Open Access This is an Open Access article distributed in accordance with the Creative Commons Attribution Non Commercial (CC BY-NC 3.0) license, which permits others to distribute, remix, adapt, build upon this work non- commercially, and license their derivative works on different terms, provided the original work is properly cited and the use is non-commercial. See: http:// creativecommons.org/licenses/by-nc/3.0/

\section{REFERENCES}

1. Grieve DJ, Cassidy RS, Green BD. Emerging cardiovascular actions of the incretin hormone glucagon-like peptide-1: potential therapeutic benefits beyond glycaemic control? Br J Pharmacol 2009; 157:1340-51.

2. Orskov C, Rabenhøj L, Wettergren A, et al. Tissue and plasma concentrations of amidated and glycine-extended glucagon-like peptide I in humans. Diabetes 1994;43:535-9.

3. Deacon CF. Circulation and degradation of GIP and GLP-1. Horm Metab Res 2004:36:761-5.

4. Knudsen LB, Pridal L. Glucagon-like peptide-1-(9-36) amide is a major metabolite of glucagon-like peptide-1-(7-36) amide after in vivo administration to dogs, and it acts as an antagonist on the pancreatic receptor. Eur J Pharmacol 1996;318:429-35.

5. Bose AK, Mocanu MM, Carr RD, et al. Glucagon-like peptide-1 can directly protect the heart against ischemia/reperfusion injury. Diabetes 2005;54:146-51.

6. Ban K, Noyan-Ashraf M, Hoefer J, et al. Cardioprotective and vasodilatory actions of glucagon-like peptide 1 receptor are mediated through both glucagon-like peptide 1 receptor-dependent and -independent pathways. Circulation 2008;117:2340-50.

7. Timmers L, Henriques JPS, de Kleijin DP, et al. Exenatide reduces infarct size and improves cardiac function in a porcine model of ischemia and reperfusion injury. J Am Coll Cardiol 2009; 53:501-10.

8. Nikolaidis LA, Mankad S, Sokos GG, et al. Effects of glucagon-like peptide-1 in patients with acute myocardial infarction and left ventricular dysfunction after successful reperfusion. Circulation 2004;109:962-5.

9. Lonborg J, Veilstrup $\mathrm{N}$, Kelbek $\mathrm{H}$, et al. Exenatide reduces reperfusion injury in patients with ST-segment elevation myocardial infarction. Eur Heart J 2012;33:1491-9.

10. Matsubara J, Sugiyama S, Sugamura K, et al. A dipeptidyl peptidase-4 inhibitor, des-fluoro-sitagliptin, improves endothelial function and reduces atherosclerotic lesion formation in apolipoprotein E-deficient mice. J Am Coll Cardiol 2012; 59:265-76.

11. Nathanson D, Zethelius B, Berne C, et al. Plasma levels of glucagon like peptide-1 associate with diastolic function in elderly men. Diabet Med 2011;28:301-5.

12. Drucker DJ. The biology of incretin hormones. Cell Metab 2006;3:153-65.

13. Ossum A, van Deurs U, Engstrom T, et al. The cardioprotective and inotropic components of the postconditioning effects of GLP-1 and GLP-1(9-36)a in an isolated rat heart. Pharmacol Res 2009;60:411-17.

14. Sonne DP, Engstrom T, Treiman M. Protective effects of GLP-1 analogues exendin-4 and GLP-1(9-36) amide against ischemia-reperfusion injury in rat heart. Regul Pept 2008;146:243-9.

15. Iwasa M, Kobayashi $\mathrm{H}$, Yasuda $\mathrm{S}$, et al. Anti-diabetic drug voglibose is protective against ischemia-reperfusion injury via GLP-1 receptors and $\mathrm{PI} 3$ kinase-Akt-eNOS pathway in rabbits. J Cardiovasc Pharmacol 2010;55:625-34.

16. Iwasa M, Yamada Y, Kobayashi $\mathrm{H}$, et al. Both stimulation of GLP-1 receptors and inhibition of glycogenolysis additively contribute to a protective effect of oral miglitol against ischaemia-reperfusion injury in rabbits. Br J Pharmacol 2011;164:119-31.

17. Thrainsdottir I, Malmberg K, Olsson A, et al. Initial experience with GLP-1 treatment on metabolic control and myocardial function in patients with type 2 diabetes mellitus and heart failure. Diab Vasc Dis Res 2004;1:40-3.

18. Sokos GG, Nikolaidis LA, Mankad S, et al. Glucagon-like peptide-1 infusion improves left ventricular ejection fraction and functional status in patients with chronic heart failure. $J$ Card Fail 2006;12:694-9.

19. Wei CM, Heublein DM, Perrella MA, et al. Natriuretic peptide system in human heart failure. Circulation 2993;88:1004-9.

20. Maeda K, Tsutamoto T, Wada A, et al. Plasma brain natriuretic peptide as a biochemical marker of high left ventricular end-diastolic pressure in patients with symptomatic left ventricular dysfunction. Am Heart J 1998;135:825-32.

21. Tsutamoto $\mathrm{T}$, Wada $\mathrm{A}$, Maeda $\mathrm{K}$, et al. Attenuation of compensation of endogenous cardiac natriuretic peptide system in chronic heart failure: prognostic role of plasma brain natriuretic peptide 
concentration in patients with chronic symptomatic left ventricular dysfunction. Circulation 1997;96:509-16.

22. Nagueh SF, Appleton CP, Gillebert TC, et al. Recommendations for the evaluation of left ventricular diastolic function by echocardiography. J Am Soc Echocardiogr 2009;22:107-33.

23. Lubien $\mathrm{E}$, DeMaria A, Krishnaswamy $\mathrm{P}$, et al. Utility of B-natriuretic peptide in detecting diastolic dysfunction: comparison with Doppler velocity recordings. Circulation 2002;105:595-601.
24. Kim M, Platt MJ, Shibasaki T, et al. GLP-1 receptor activation and Epac2 link atrial natriuretic peptide secretion to control of blood pressure. Nat Med 2013; 2013;19:567-75.

25. Bhashyam S, Fields AV, Patterson B, et al. Glucagon-like peptide-1 increases myocardial glucose uptake via p38alpha MAP kinase-mediated, nitric oxide-dependent mechanisms in conscious dogs with dilated cardiomyopathy. Circ Heart Fail 2010;3:512-21. 